\title{
Two kinds of imidazole chloride salt dissolving performance study of coniferous wood pulp
}

\author{
Zhiqing GUO ${ }^{1, a}$, Yu WANG ${ }^{1, b}$ and Jintian HUANG ${ }^{1, c^{*}}$ \\ ${ }^{1}$ college of material science and art design, Inner Mongolia agricultural university, Hohhot 010018 , \\ Inner Mongolia, China \\ a517986068@qq.com, b499436197@qq.com, cjintian_h@163.com \\ * Jintian HUANG
}

Keywords: Coniferous wood pulp, ionic liquid, Regenerated cellulose, Solubile property

Abstract. Two imidazole type ionic liquids-1-allyl-3-methyl imidazole chloride salt [AMIM]Cl and 1-butyl-3- methyl imidazole chloride [BMIM]Cl-were used as solvent of cellulose, and under low temperature dissolved cellulose directly. In this paper, we found that cellulose was dissolved [AMIM]Cl ionic liquid within 3 min under the condition of $80{ }^{\circ} \mathrm{C}$ and [BMIM]Cl ionic liquid within 3 min under the condition of $100{ }^{\circ} \mathrm{C}$.

\section{Introduction}

People pay more attention to development and utilization of natural renewable resources with issue of oil, gas, coal and other non-renewable resources depleting, the growing population and the deteriorating environment around the world. Cellulose is nature's most abundant natural renewable resources, and widely used in Paper making, clothing, construction, food, etc in industrial areas ${ }^{[1]}$. Cellulose is a natural high molecular polymer with a linear structure that exist within crystalline and amorphous regions ${ }^{[2]}$, which making it hard for common solvents to dissolve cellulose, and resulting in a difficult to use natural cellulose renewable resources. Therefore, looking for a good and effective solvent system is the key to solving this problem.

Ionic liquids are an environmentally friendly solvent, which have high catalytic activity, no vapor pressure, chemical stability, strong polar, reusable, etc. advantages [3,4]. And have good dissolute -ion properties to cellulose. This study selected 1-allyl-3-methyl imidazole chloride salt [AMIM] C 1 and 1-butyl-3- methyl imidazole chloride [BMIM] $\mathrm{Cl}$ two ionic liquids as the solvent of cellulose, exploring two imidazolium chloride dissolution properties to the cellulose.

\section{Experimental Section}

Reagents, materials. Softwood pulp; 1-allyl-3-methylimidazolium chloride [AMIM]C1, 1-butyl-3-methylimidazolium chloride [BMIM]Cl, purity: 99\% ( The Lanzhou materialized, Chines e Academy of Sciences ); Nitrate silver ( precious metal products Co., Ltd. Dongguan City Bank ); Concentrated nitric acid and anhydrous ethanol were of analytical grade. Deionized water was used throughout the experiments.

Equipments. Micro plant grinding machine, DF-2 magnetic stirring oil bath pot, Vacuum drying oven, OPTEC-BK-5000 biological microscope.

Extraction of cellulose. The softwood pulp were cut into long strips about $0.5 \mathrm{~cm}$, then crushed by mill after placed in $105^{\circ} \mathrm{C}$ oven drying $72 \mathrm{~h}$, and sieved 80 mesh pulp. Weighed wood pulp $1.05 \mathrm{~g}$ and $25 \mathrm{~mL}$ of nitric acid-ethanol ${ }^{[5]}$ solution put into a clean Erlenmeyer flask, then heated in boiling water bath. Suction filtration with a G4 glass frit funnel after one hour. This procedure was repeated four times, and then washed three times with nitric acid-ethanol solution, and then washed repeatedly with about $70{ }^{\circ} \mathrm{C}$ hot water, finally washed 3 times with anhydrous ethanol, then the glass frit funnel at $105{ }^{\circ} \mathrm{C}$ inside the oven drying after the filtrate was drained out, the wood pulp cellulose were obtained after completely dried out.

Wood pulp cellulose in [AMIM]Cl ionic liquid dissolution and regeneration. Dissolving wood pulp cellulose: put $[\mathrm{AMIM}] \mathrm{Cl}$ ionic liquid $5 \mathrm{~g}$ that were weighed in a clean three-necked flask, 
and then added wood pulp cellulose $0.2 \mathrm{~g}$ into it. Set up 4 dissolution temperatures that were 50, 60, $70,80\left({ }^{\circ} \mathrm{C}\right)$, and 6 dissolution times that were $0,3,5,6,8,15(\mathrm{~min})$. Taking samples at the same temperature but in the different dissolution times as described above. Then observe the dissolution process of the cellulose pulp after the samples were placed on a microscope stage. After until complete dissolution, added in deionized water to remove [AMIM]Cl ionic liquid, and using $0.1 \mathrm{~mol} / \mathrm{L}$ silver nitrate test solution, there was no white precipitate.

Wood pulp cellulose in [BMIM]Cl ionic liquid dissolution and regeneration. Dissolving wood pulp cellulose: Put [BMIM]Cl ionic liquid 5g that were weighed in a clean three-necked flask, and then added wood pulp cellulose $0.2 \mathrm{~g}$ into it. Set up 4 dissolution temperatures that were 70,80 , $90,100\left({ }^{\circ} \mathrm{C}\right)$, and 6 dissolution times that were $0,3,5,6,8,15(\mathrm{~min})$. Taking samples at the same temperature but in the different dissolution times as described above. Then observe the dissolution process of the cellulose pulp after the samples were placed on a microscope stage. After until complete dissolution, added in deionized water to remove [BMIM]Cl ionic liquid, and using $0.1 \mathrm{~mol} / \mathrm{L}$ silver nitrate test solution, there was no white precipitate.

Recycle of ionic liquids. The mixed filtrate contained the deionized water that separated regenerated cellulose and the ionic liquid were distilled under reduced pressure, and the deionized water was removed, then the ionic liquid could be recovered after dried at $40^{\circ} \mathrm{C} 48 \mathrm{~h}$ in a vacuum oven.

\section{Result and Discussion}

Wood pulp cellulose's dissolution temperature and time in [AMIM]Cl ionic liquid. Record the relationship between Wood pulp cellulose's dissolution temperature and time in [AMIM]Cl ionic liquid. The results are listed in Table 1. According to the results of Table 1, it show the shorter time to be dissolved wood pulp cellulose in [AMIM]Cl ionic liquid along with the higher dissolved temperature. The cellulose can be completely dissolved in the $15 \mathrm{~min}$ when the dissolved temperature was raised to $60{ }^{\circ} \mathrm{C}$, and the cellulose can be completely dissolved in the 3 min when the dissolved temperature was raised to $80{ }^{\circ} \mathrm{C}$.

Table 1 The dissolution time of Cellulose pulp in [AMIM] $\mathrm{Cl}$ ionic liquid at different dissolution temperatures

\begin{tabular}{|c|c|c|c|c|c|c|c|}
\hline \multirow{2}{*}{$\begin{array}{c}\text { Temperature } \\
{\left[{ }^{\circ} \mathrm{C}\right]}\end{array}$} & \multicolumn{7}{|c|}{ Time [min] } \\
\hline & 0 & 3 & 5 & 6 & 8 & 15 & 30 \\
\hline 50 & Undissolved & Undissolved & Undissolved & / & Undissolved & $\begin{array}{l}\text { Partially } \\
\text { dissolved }\end{array}$ & $\begin{array}{c}\text { Most } \\
\text { dissolved }\end{array}$ \\
\hline 60 & Undissolved & Undissolved & $\begin{array}{l}\text { Partially } \\
\text { dissolved }\end{array}$ & l & $\begin{array}{c}\text { Most } \\
\text { dissolved }\end{array}$ & Dissolved / & \\
\hline 70 & Undissolved & $\begin{array}{c}\text { Most } \\
\text { dissolved }\end{array}$ & Dissolved & l & I & l & \\
\hline 800 & Undissolved & Dissolved & I & I & I & I & \\
\hline
\end{tabular}

Wood pulp cellulose's dissolution temperature and time in [BMIM]Cl ionic liquid. Record the relationship between Wood pulp cellulose's dissolution temperature and time in [BMIM]Cl ionic liquid. The results are listed in Table 2.

Table 2 showed that the dissolution time of wood pulp cellulose in ionic liquids decreasing along with the dissolution temperature rising. The cellulose could be completely dissolved in the $8 \mathrm{~min}$ when the dissolution temperature was raised to $80^{\circ} \mathrm{C}$. And the cellulose could be completely dissolved in the $3 \mathrm{~min}$ when the dissolution temperature was raised to $100^{\circ} \mathrm{C}$. 
Table 2 The dissolution time of Cellulose pulp in [BMIM] $\mathrm{Cl}$ ionic liquid at different dissolution temperature

\begin{tabular}{|c|c|c|c|c|c|c|}
\hline \multirow{2}{*}{$\begin{array}{c}\text { Temperature } \\
{\left[{ }^{\circ} \mathrm{C}\right]}\end{array}$} & \multicolumn{6}{|c|}{ Time [min] } \\
\hline & 0 & 3 & 5 & 6 & 8 & 15 \\
\hline 70 & Undissolved & Undissolved & Undissolved & Undissolved & Undissolved & Undissolved \\
\hline 80 & Undissolved & $\begin{array}{l}\text { Partially } \\
\text { dissolved }\end{array}$ & $\begin{array}{c}\text { Most } \\
\text { Dissolved }\end{array}$ & 1 & Dissolved & 1 \\
\hline 90 & Undissolved & $\begin{array}{c}\text { Most } \\
\text { dissolved }\end{array}$ & Dissolved & I & I & I \\
\hline 100 & Undissolved & Dissolved & 1 & I & 1 & 1 \\
\hline
\end{tabular}

The dissolution mechanism of cellulose in ionic liquids. Cellulose was dissolved in the [AMIM] $\mathrm{Cl}$ and [BMIM] $\mathrm{Cl}$ ionic liquid. Cellulose was dissolved to speed up in the ionic liquid with the temperature rising, and the cellulose could be quickly dissolved in the ionic liquid when the temperature reached a certain level. From Fig. 1 and Fig. 2 we could know, The result of cellulose dissolution time shortened for cellulose hydrogen bonds between the molecular chains was opened when the probability of ions attack the cellulose molecule chain hydroxy increase when imidazole cation was the electron acceptor center and chlorine ion was the electron donor center ${ }^{[6]}$. Cellulose was dissolved by 1-allyl-3-methylimidazolium chloride compared to 1-butyl-3-methylimidazolium chloride at a lower temperature, due to the presence of a double bond in the imidazolium cation, so that increase the degree of cation-electron-deficient, offensive cellulose hydroxyl groups on the oxygen atom to accelerate dissolution of cellulose ${ }^{[7]}$.

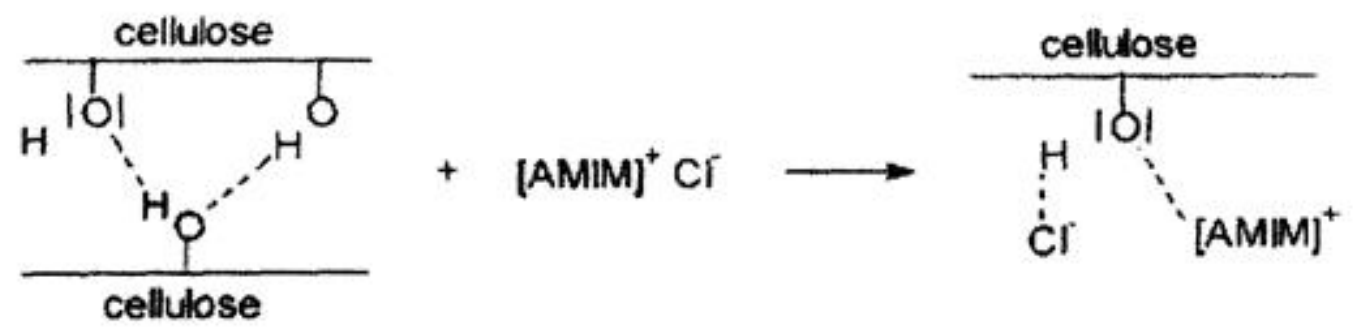

Fig. 1 The dissolution mechanism of wood pulp cellulose in [AMIM]Cl ionic liquid

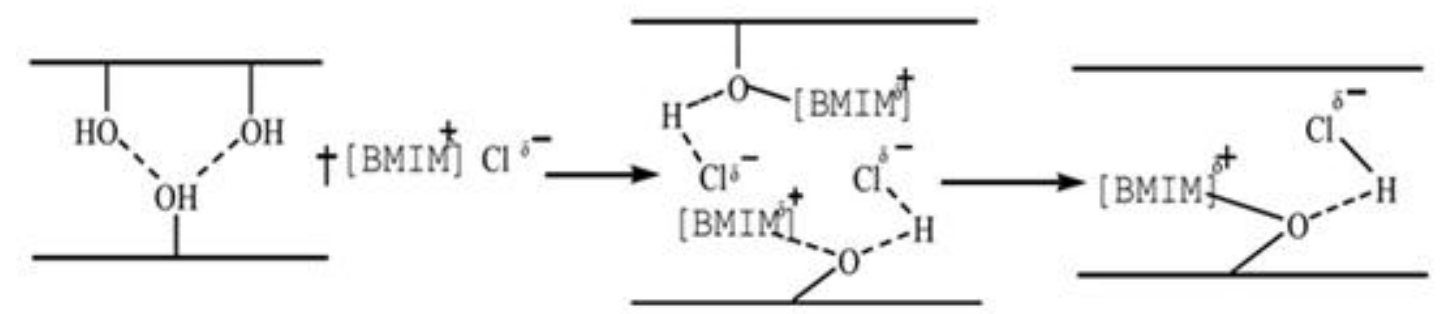

Fig. 2 The dissolution mechanism of wood pulp cellulose in [BMIM]Cl ionic liquid

\section{Conclusion}

(1) Softwood could be directly dissolved by 1-allyl-3-methylimidazolium chloride [AMIM]Cl and 1-butyl-3-methylimidazolium chloride [BMIM]Cl ionic liquid after it was dried out and crushed 
out and extracted by nitric acid-ethanol solution.

(2) The frequency was increased of chloride attack fiber hydrogen bonds along with rising temperatures, and it made the cellulose quickly dissolved in ionic liquids.

(3) The cellulose almost completely dissolved in 30s in [AMIM]Cl ionic liquid at the condition of $80{ }^{\circ} \mathrm{C}$, and it has been dissolved completely in 240s. And the cellulose has been dissolved in $240 \mathrm{~s}$ in [BMIM] $\mathrm{Cl}$ ionic liquid at the condition of $100^{\circ} \mathrm{C}$.

(4) The cellulose could be more quickly dissolved in [AMIM]Cl ionic liquid than in[BMIM]Cl ionic liquid at lower temperature.

\section{Acknowledgements}

This work was supported by the Inner Mongolia Autonomous Region applied technology research and development funds plan (20130317) and science research innovation projects of the Inner Mongolia Autonomous Region for graduate under grant no.B20141012902Z.

\section{References}

[2] Y. nishiyama, J. Sugiyama, H. Chanzy, et al. Crystal structure and hydrogen bonding system in cellulose Iafrom synchrotron X-ray and neutron fiber diffraction. J. Am. Chem. Soc, 125(2003) 14300-14306.

[3] T. Long, Y.F. Denf, S. Gan, J. Chen. Application of Choline Chloride $x Z n C 12$ Ionic Liquids for preparation of Biodiesel. CHINESE. J. CHEM. ENG,18(2010) 322-327.

[4] Y. Lu, Q.F. Sun, H.P. Yu, et al. Dissolution and Regeneration of Cellulose and Development in Processing Cellulose-Based Materials with Ionic Liquids [J]. CHINESE J ORG CHEM, 30(2010) 593-1602.

[5] L.F. Wang, Y.C. Chen. Determination the content of cellulose by nitric acid-ethanolmethod. Acc. Chem. Res, 22(2011) 52-55.

[6] W.W. Yang, S.J. Wang. Study on dissolubility of microcrystalline cellulose in imidazole ionic liquids. Modern Chemical Industry, 30(2010) 166-169.

[7] M.L. Wang, H.J. Zang, B.X. Cai, et al. Dissolubility of cellulose in the ionic liquid [AMMor] Cl / [AMIM] Cl mixed solvent. CHEM. J. CHINESE. U, 30(2009) 1469 1472.

Reference to a book:

[1] Jie Gao, Liegui Tang. Cellulose Science, Science Press, 1999. 